\title{
Effects of Different Concentrations of Selenium on Photosynthetic Pigment Content of Perilla frutescens
}

\author{
Renyan Liao \\ Ya'an Polytechnic College, Ya'an 62500, China \\ 51699474@qq.com
}

\begin{abstract}
Keywords: Selenium; Perilla frutescens; Photosynthetic pigment
Abstract: A pot experiment was conducted to study the effects of different concentrations of selenium (Se) on photosynthetic pigment content of Perilla frutescens. The results showed that Se treatment had significant effect on contents of chlorophyll $a$, chlorophyll $b$, carotenoid and total chlorophyll. With Se concentrations increased, the photosynthetic pigment content showed a different trend. However, as a whole, the content of photosynthetic pigments tends to decrease. When Se concentration was $0 \mathrm{mg} / \mathrm{kg}$, contents of chlorophyll $a$, carotenoid and total chlorophyll reached the peak. However, chlorophyll $b$ content reached the peak when Se concentration was 5 $\mathrm{mg} / \mathrm{kg}$, which increased by $10.13 \%$ compared with the control. Therefore, Se can reduce the photosynthetic pigment content of $P$. frutescens. When Se concentration was low, $P$. frutescens reaction was not obvious, but with the increase of the concentration, the photosynthetic pigment content significantly reduced.
\end{abstract}

\section{Introduction}

Perilla frutescens is an annual bush, growing to a height of 4 feet [1], which is a traditional crop of Korea, China, Japan, India, Nepal, and Thailand. It is cultivated for its essential oils and medicinal uses [2]. Selenium (Se) is a naturally occurring element essential to some organisms, including bacteria, some green algae and mammals. Although higher plants do not require Se, they take it up due to its chemical and physical similarities to sulfur [3]. For higher plants, Se is beneficial at low concentrations, but elevated levels of this element can cause toxicity [4]. For nonaccumulator plants like Arabidopsis thaliana, tissue Se concentrations higher than $2 \mathrm{mg} / \mathrm{kg}$ cause toxicity [5] and can result in an approximately $10 \%$ reduction of biomass yield without the appearance of visible symptoms [6]. Se treatment also has effect on photosynthetic pigments accumulation. In salt-stressed condition, Se could increase in photosynthetic pigment concentration. Research has shown an increase in chlorophyll $a$ and $b$, carotenoid contents as well as the net photosynthetic rate [7-8]. In addition, lower Se dose $(6 \mathrm{mg} / \mathrm{kg})$ improved the plant growth mainly by enhancing photosynthesis, stomatal conductance, carboxylation efficiency and Rubisco content in the flue-cured tobacco leaves. However, the inhibition of excess Se on tobacco growth might be due to high accumulation of $\mathrm{Se}$ in roots and the damage of photosynthesis in leaves [9]. Therefore, this experiment used different concentrations of Se to study the changes of photosynthetic pigment of $P$. frutescens in Se-contained soil.

\section{Materials and Methods}

Materials. The experiments were conducted at Sichuan Agricultural University $\left(30^{\circ} 42^{\prime} \mathrm{N}, 103^{\circ} 51^{\prime}\right.$ E), Wenjiang, Chengdu, Sichuan, China. $P$. frutescens seeds are purchased from the market. Se is purchased from Chengdu Kelong chemical reagent factory. All chemicals used in experiments were of analytical grade.

Experimental Design. The soil samples were air-dried and passed through a 5-mm mesh in April 2017 , and then $3.0 \mathrm{~kg}$ of soil was weighed into each polyethylene pot $18 \mathrm{~cm} \times 26 \mathrm{~cm}$ (height $\times$ diameter). $\mathrm{Na}_{2} \mathrm{SeO}_{3}$ solution was added to the soil to divide the Se content into 0 (control), 5, 10, 25 , 50,75 and $100 \mathrm{mg} / \mathrm{kg}$. The soils were mixed immediately and again after 4 weeks, during this period soil moisture was kept at $80 \%$. Seeds were sterilized in $10 \% \mathrm{Na}_{3} \mathrm{PO}_{4}$ solution for 5 min, rinsed in distilled water five times, and were placed on 9-cm-diameter Petri dishes with three layers 
of filter paper moistened with distilled water and germinated at $25{ }^{\circ} \mathrm{C}$ in darkness. Seeds were considered germinated when the seed coat was broken and a radical was visible. After germination, seeds were planted in seedling tray filled with nursery substrate. When the third leaf expanded, uniform seedlings were transplanted into the previously prepared polyethylene pots, four plants seedlings per pot, each treatment repeated three times, randomly placed, and routinely administered. After one month of plants growing, the upper mature leaves were collected to determine the chlorophyll $a$, chlorophyll $b$ and carotenoid content [10].

Statistical Analyses. Statistical analysis was carried out by using SPSS 20.0 statistical software. The data were analyzed by one-way ANOVA, with the least significant difference at the $5 \%$ confidence level.

\section{Results and Discussion}

Chlorophyll $\boldsymbol{a}$ Content of $\boldsymbol{P}$. frutescens. Chlorophyll $a$ content of $P$. frutescens gradually decreased with increasing Se concentration (Fig. 1). And the difference between each treatment was extremely significant. Compared with control, when Se concentrations were 5, 10, 25, 50, 75, $100 \mathrm{mg} / \mathrm{kg}$, chlorophyll $a$ content decreased by $3.80 \%, 6.90 \%, 15.90 \%, 18.60 \%, 32.50 \%$ and $36.40 \%$, respectively, compared with control.

Chlorophyll $\boldsymbol{b}$ Content of $\boldsymbol{P}$. frutescens. Se treatment had significant effect on chlorophyll $b$ content (Fig. 2). Within the range of $0-100 \mathrm{mg} / \mathrm{kg}$, chlorophyll $b$ content increased firstly and then decreased with the increase of soil Se concentration, and reached the peak when soil Se concentration was $5 \mathrm{mg} / \mathrm{kg}$, which increased by $10.13 \%$ compared with the control. However, when Se concentrations were $25,50,75,100 \mathrm{mg} / \mathrm{kg}$, chlorophyll $b$ contents were lower than control, which decreased by $17.26 \%, 13.11 \%, 22.79 \%$ and $21.81 \%$, respectively, compared with control.

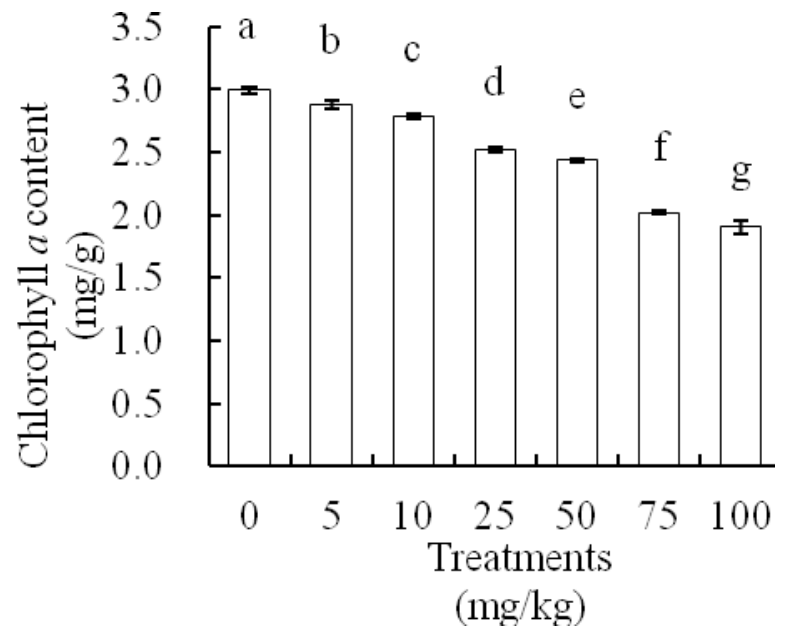

Fig. 1 Chlorophyll $a$ content of $P$. frutescens

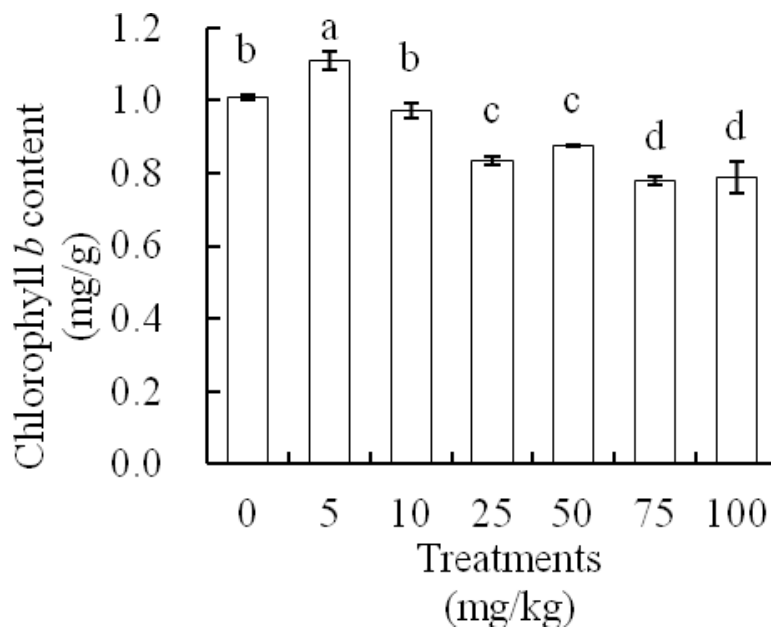

Fig. 2 Chlorophyll $b$ content of $P$. frutescens

Carotenoid Content of $\boldsymbol{P}$. frutescens. Se treatment had significant effect on carotenoid content (Fig. 3). With Se concentrations increased, carotenoid content decreased firstly, and then increased, decreased lastly. In addition, when Se concentration was $0 \mathrm{mg} / \mathrm{kg}$, carotenoid content was the highest. Compared with control, when Se concentrations were 5, 10, 25, 50, 75 and $100 \mathrm{mg} / \mathrm{kg}$, carotenoid content decreased by $2.29 \%, 8.17 \%, 10.52 \%, 2.71 \%, 20.05 \%$ and $26.11 \%$, respectively, compared with control.

Total chlorophyll content of $\boldsymbol{P}$. frutescens. With the increase of Se concentration, total chlorophyll content showed a downward trend (Fig. 4). Total chlorophyll content when the Se content was $5 \mathrm{mg} / \mathrm{kg}$ was not significantly different from the control. When Se concentrations were $10,25,50,75$ and $100 \mathrm{mg} / \mathrm{kg}$, total chlorophyll contents decreased by $6.98 \%, 14.71 \%, 15.64 \%$, $30.30 \%$ and $34.36 \%$, respectively, compared with control. 


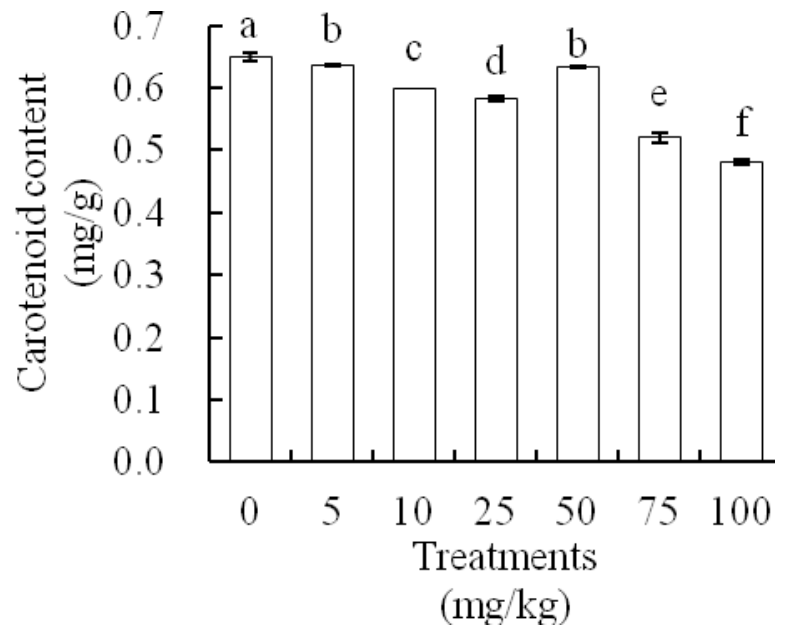

Fig. 3 Carotenoid content of $P$. frutescens

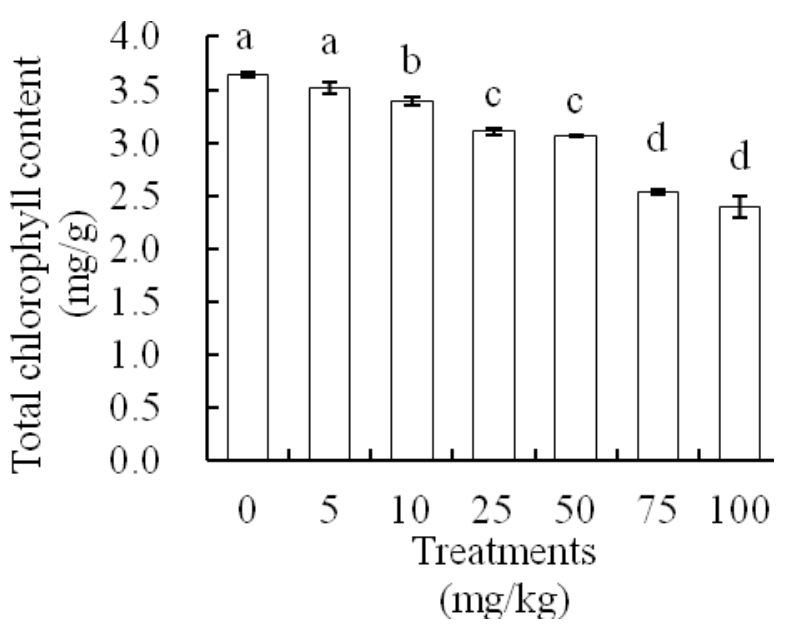

Fig. 4 Total chlorophyll content of $P$. frutescens
Chlorophyll $\boldsymbol{a} / \boldsymbol{b}$ of $\boldsymbol{P}$. frutescens. As shown in Fig. 5, Se treatment had effect on chlorophyll $a / b$. With increasing Se concentration, chlorophyll $a / b$ decreased firstly, and then increased, decreased finally. And when Se concentration was $25 \mathrm{mg} / \mathrm{kg}$, chlorophyll $\mathrm{a} / \mathrm{b}$ reached the peak.

\section{Conclusions}

Under Se treatment conditions, photosynthetic pigment content showed a different trend. With increasing Se concentration, chlorophyll $a$ content and total chlorophyll content decreased, and the chlorophyll $b$ content increased firstly and then decreased. Carotenoid content and chlorophyll $a / b$ decreased firstly, and then increased, decreased finally. When Se concentration was $0 \mathrm{mg} / \mathrm{kg}$, contents of chlorophyll $a$, carotenoid and total chlorophyll reached the peak. However, chlorophyll $b$ content reached the peak when Se concentration was $5 \mathrm{mg} / \mathrm{kg}$. In conclusion, Se can reduce photosynthetic pigment content of $P$. frutescens. When Se concentration was low, P. frutescens reaction was not obvious, but with the increase of the concentration, photosynthetic pigment content significantly reduced.

\section{Acknowledgements}

This work was financially supported by the Application Technology Research and Development Project of Ya'an (2017yyjskf14).

\section{References}

[1] M. Ito, M. Toyoda, S. Kamakura and G. Honda: Journal of Essential Oil Research Vol. 14(2002), p. 416.

[2] J. K. Lee and O. Ohnishi: Breeding Science, Vol. 51(2002), p. 247.

[3] H. El-Ramady, N. Abdalla, T. Alshaal and H. El-Henawy: Environmental Chemistry Letters Vol. 13(2015), p. 359.

[4] N. Terry, M.P. de Souza and A.M. Tarun: Annual Review of Plant Physiology and Plant Molecular Biology Vol. 51(2000), p.401. 
[5] R.L. Mikkelsen, A.L. Page and F.T. Bingham: Selenium in Agriculture and the Environment Vol. 26(1989), p.64.

[6] E. Kabata-Pendias: Trace elements in soils and plants, $4^{\text {th }}$ ed. CRC Press/Taylor \& Francis Group, LCC, Boca Raton, 2011.

[7] W. Jozwiak, M. Mleczek and B. Pllitycka: Fresenius Environmental Bulletin Vol. 25(2016), p.142.

[8] C.Q. Jiang, C.L. Zu, D.J. Lu, Q.S. Zheng, J. Shen, H.Y. Wang and D.C. Li: Scientific Reports Vol. 7(2017) p. 42039.

[9] C.Q. Jiang, C.L. Zu, J. Shen, F.W. Shao and T. Li: Acta Societatis Botanicorum Poloniae Vol. 84(2015), p. 71.

[10] Z.B. Hao, J. Cang and Z. Xu: Plant Physiology Experiment (Harbin Institute of Technology Press, Harbin, China 2004). 